\title{
Peritonite em cães
}

\author{
Peritonitis in dogs \\ Marina Zimmermann ${ }^{1}$ Alceu Gaspar Raiser ${ }^{2}$ Alexandre Mazzanti ${ }^{3}$ \\ Sonia Terezinha dos Anjos Lopes ${ }^{3}$ Fabiano Zanini Salbego ${ }^{1}$
}

\section{- REVISÃO BIBLIOGRÁFICA -}

\section{RESUMO}

A peritonite em cães ainda é caracterizada como uma severa complicação de afeç̧ões na cavidade abdominal. Define-se a enfermidade como uma inflamação do peritônio, na maioria das vezes com prognóstico reservado, e que pode ser fatal. Ela se apresenta de diferentes formas, sendo a séptica a mais comum, em que microorganismos patogênicos proliferam rapidamente, e determinam processo infeccioso grave. Devido à importância da peritonite em cães, são abordados a etiopatogenia, os métodos diagnósticos e a conduta terapêutica mais apropriada. Para um prognóstico favorável, o diagnóstico precoce e o tratamento eficaz são fundamentais.

Palavras-chave: peritônio, cavidade abdominal, infecção, cão.

\section{ABSTRACT}

Peritonitis in dogs is still characterized as a severe complication of diseases in the abdominal cavity. Peritonitis is an inflammation of the peritoneum which most often is given an adverse prognostic with the potential of fatal evolution. It presents itself in three forms: aseptic, septic and combined. The septic form is the most common, in which the pathogenic microorganisms rapidly proliferate incurring a severe infectious process. Because of the great importance of this disease, the etiopathogeny, diagnosis methods, and more effective therapy was reviewed with emphasis in new forms of treatment. A favorable prognostic depends on the early diagnostic and the correct treatment for each occurring form.

Key words: peritoneum, abdmomen, infection, dogs.

\section{INTRODUÇÃO}

A peritonite é responsável por complicações graves em intervenções cirúrgicas na cavidade abdominal, porém, em face de novos tratamentos, o prognóstico tornou-se mais favorável, embora muitos casos ainda evoluam para choque séptico e morte. A peritonite consiste em inflamação do peritônio, com classificação variável em relação à origem (primária, secundária), ao grau de contaminação (asséptica, séptica, mista) e à extensão, segundo a qual pode ser localizada (limitada a uma área anatômica específica) ou difusa (comprometendo de forma generalizada a membrana peritoneal).

$\mathrm{Na}$ peritonite primária, que representa menos de $1 \%$ dos casos, microorganismos migram para a cavidade abdominal por via hematógena ou linfática (CROWE Jr \& BJORLING 1998; SWANN \& HUGHES, 2000; BEAL, 2005; FERRAZ \& FERRAZ, 2005). Pode haver, também, contaminação retrógrada através da bolsa ovariana (por contaminação ascendente a partir de útero com infecção), desde a cavidade torácica (pelo arco lombocostal) e por migração transmural de bactérias intestinais endógenas em casos de isquemia ou de choque sistêmico (CROWE Jr \& BJORLING, 1998; SWANN \& HUGHES, 2000).

\footnotetext{
${ }^{1}$ Programa de Pós-graduação em Medicina Veterinária (PPGMV), Centro de Ciências Rurais (CCR), Universidade Federal de Santa Maria (UFSM), Santa Maria, RS, Brasil.

²Departamento de Clínica de Pequenos Animais (DCPA), CCR, UFSM, Santa Maria, RS, Brasil. E-mail: raisermv@smail.ufsm.br. Autor para correspondência.

${ }^{3}$ DCPA, CCR, UFSM, Santa Maria, RS, Brasil.
} 
A peritonite secundária decorre de ferida penetrante na cavidade abdominal, podendo ainda estar associada a procedimento cirúrgico, a traumatismos (ruptura no trato urinário - uroperitônio) ou a enfermidades da cavidade abdominal, como ruptura de útero com piometra (Figura 1b) ou de abscessos (hepático e prostático), à perfuração de víscera oca por corpo estranho, que migra a partir de seu lume, ou por projétil de arma de fogo, dentre outras. O paciente com peritonite secundária sempre requer intervenção cirúrgica na cavidade abdominal (BRAY, 1996; CROWE Jr \& BJORLING, 1998; SWANN \& HUGHES, 2000; FERRAZ \& FERRAZ, 2005; JUTKOWITZ, 2005; RIESER, 2005), pois ocorre alta taxa de mortalidade se não for tratada adequadamente, podendo evoluir com formação de abscessos, sepse e insuficiência múltipla de órgãos (WONG, 2005).

A peritonite asséptica pode ser química ou mecânica. Irritantes químicos como bile (Figura 1a), secreção gástrica ou pancreática, urina ou contraste a base de bário, usado em radiologia, extravasados na serosa abdominal determinam peritonite química (BRAY, 1996; STAATZ, 2002). A presença de drenos ou cateteres, talco de luvas, fio de sutura, fios de gaze ou compressa causam peritonite mecânica (BRAY, 1996; SWANN \& HUGHES, 2000; PLUNKETT, 2001). Os autores desta revisão consideram que o uso inadequado de gaze, de compressa (que friccionem a serosa) ou de instrumental cirúrgico durante abordagem abdominal também determina inflamação do peritônio em grau variável. Por essa razão, recomendam dar preferência ao uso de aspiradores para enxugar a área operatória.

BRAY (1996) cita que mais de 50\% das peritonites sépticas decorrem de deiscência em intervenções cirúrgicas em órgãos ocos. A peritonite bacteriana tem desenvolvimento rápido e com alto risco de vida, associado a microorganismos virulentos, principalmente bactérias entéricas, tanto anaeróbicas quanto aeróbicas (BRAY, 1996; CROWE Jr \& BJORLING, 1998). O trato gastrintestinal é colonizado por mais de 400 espécies de bactérias, sendo que a microbiota dominante é composta por Bacteróides, Eubacterium, Clostridium, Streptococos, Escherichia coli, Klebsiella e Pseudomonas (BOURGOIN et al., 2004). SWANN \& HUGHES (2000) relatam que a Escherichia coli, o Clostridium sp e o Streptococcus faecalis são os microorganismos mais observados na peritonite bacteriana, o que reflete alta prevalência de complicações gastrintestinais. Para PLUNKETT (2001), a peritonite bacteriana, envolve um agrupamento de microorganismos anaeróbicos (Clostridium spp, Peptostreptococcus spp, e Bacteroides spp) e aeróbicos (Escherichia coli, Klebsiella spp e Proteus spp).

Obstruções, estrangulamentos, dilatações mecânicas ou até mesmo alterações em que se observem as alças intestinais macroscopicamente intactas provocam alteração na sua permeabilidade, facilitando a migração de bactérias para a cavidade abdominal. Pode haver disseminação desses microorganismos através da corrente circulatória gerando um quadro de septicemia, o qual pode levar o animal a óbito se não for instituído tratamento apropriado (CROWE Jr \& BJORLING 1998).

A peritonite mista decorre da evolução de uma peritonite mecânica ou química complicada pela presença de bactérias por contaminação ascendente (drenos ou ruptura de trato urinário, por exemplo) ou por migração transmural, especialmente a partir do trato gastrintestinal.

Considerando a multiplicidade de fatores causadores de peritonite e a dificuldade em tratá-la, tem-se por objetivo apresentar informações recentes sobre essa enfermidade, visando a estabelecer padrões de conduta que ofereçam maior possibilidade de sucesso em sua terapia.

\section{Fisiopatologia}

A cavidade abdominal e as vísceras nela contidas são revestidas por membrana serosa que possui grandes coletores linfáticos na superfície inferior do diafragma, os quais drenam a linfa produzida nesta cavidade. Em decorrência da ação da gravidade e do movimento do diafragma, o líquido peritoneal se desloca em sentido cranial e dorsal, ao longo da superfície diafragmática do fígado. Quando se injeta um contraste na cavidade abdominal, esse pode espalhar-se em 15 minutos, demonstrando, desta maneira, como um foco localizado de infecção pode disseminar-se rapidamente (DULISH, 1996).

A inflamação do peritônio e a presença de bactérias ou de componentes irritantes estimulam a liberação de substâncias vasoativas, proteases celulares, endotoxinas e fixação pelo complemento com ativação do ácido aracdônico e, em conseqüência, há ativação e agregação plaquetária. Esses eventos causam dilatação e aumento na permeabilidade microvascular em área extensa dessa serosa, com perda importante de líquido, eletrólitos e proteínas do plasma para a cavidade abdominal. A fibrina e os produtos da inflamação obstruem os linfáticos e há seqüestro desse líquido com resultante hipovolemia e hipoproteinemia, as quais, associadas ao vômito e/ou à ingestão inadequada de líquidos, resultam em choque 
hipovolêmico (SWANN \& HUGHES, 2000; PAPAZOGLOU \& RALLIS, 2001).

A espoliação da volemia, associada com diminuição na perfusão renal, causa acidose e hipercalemia, além de distúrbios de coagulação por agregação de células sangüíneas na microcirculação (PAPAZOGLOU \& RALLIS, 2001). A possibilidade de coagulação intravascular disseminada (Figura 1c) é potencializada na presença de sepse.

A redução na perfusão esplâncnica causa isquemia visceral, a qual, associada ao edema no intestino, em decorrência da inflamação, pode comprometer a integridade de mucosa, favorecer a translocação bacteriana e estabelecer choque séptico. O processo inflamatório pode generalizar-se e afetar múltiplos tecidos e órgãos, caracterizando a síndrome da resposta inflamatória sistêmica (SRIS) (SWANN \& HUGHES, 2000; PAPAZOGLOU \& RALLIS, 2001).

A presença de fibrina, nas peritonites, visa a selar as perfurações viscerais e localizar a infecção, no que é auxiliada pelo omento. Este, devido a sua mobilidade, rica vascularização sangüínea e linfática, é capaz de tornar localizada a peritonite decorrente de ruptura visceral e aumentar a tensão de oxigênio na área lesionada, diminuindo a possibilidade de proliferação de microorganismos anaeróbicos. Além disso, promove revascularização de tecidos isquêmicos, participa na absorção de bactérias e corpos estranhos e colabora no afluxo de células inflamatórias para o local da agressão (BRAY, 1996).

Na presença de uroperitônio, ocorre migração de líquido para a cavidade abdominal, com espoliação dos meios intracelular e intersticial, devido à presença de grandes partículas osmoticamente ativas, como a creatinina, resultando em instabilidade hemodinâmica e acidose metabólica (RIESER, 2005).

Considerando os aspectos fisiopatológicos alterados na vigência de peritonite, verifica-se comprometimento na perfusão tecidual, acidose metabólica, sepse, distúrbios de coagulação e insuficiência múltipla de órgãos que culminam com o óbito do paciente.

\section{Diagnóstico}

O diagnóstico de peritonite deve ser apoiado na anamnese, nos sinais clínicos, no lavado peritoneal diagnóstico, em dados laboratoriais e no uso de imagem. Na anamnese, deve-se identificar a presença de traumatismo agudo, intervenção cirúrgica ou enfermidade relacionada às vísceras da cavidade abdominal.

Clinicamente, os sinais variam dependendo da causa e da localização da inflamação. Hipertermia,

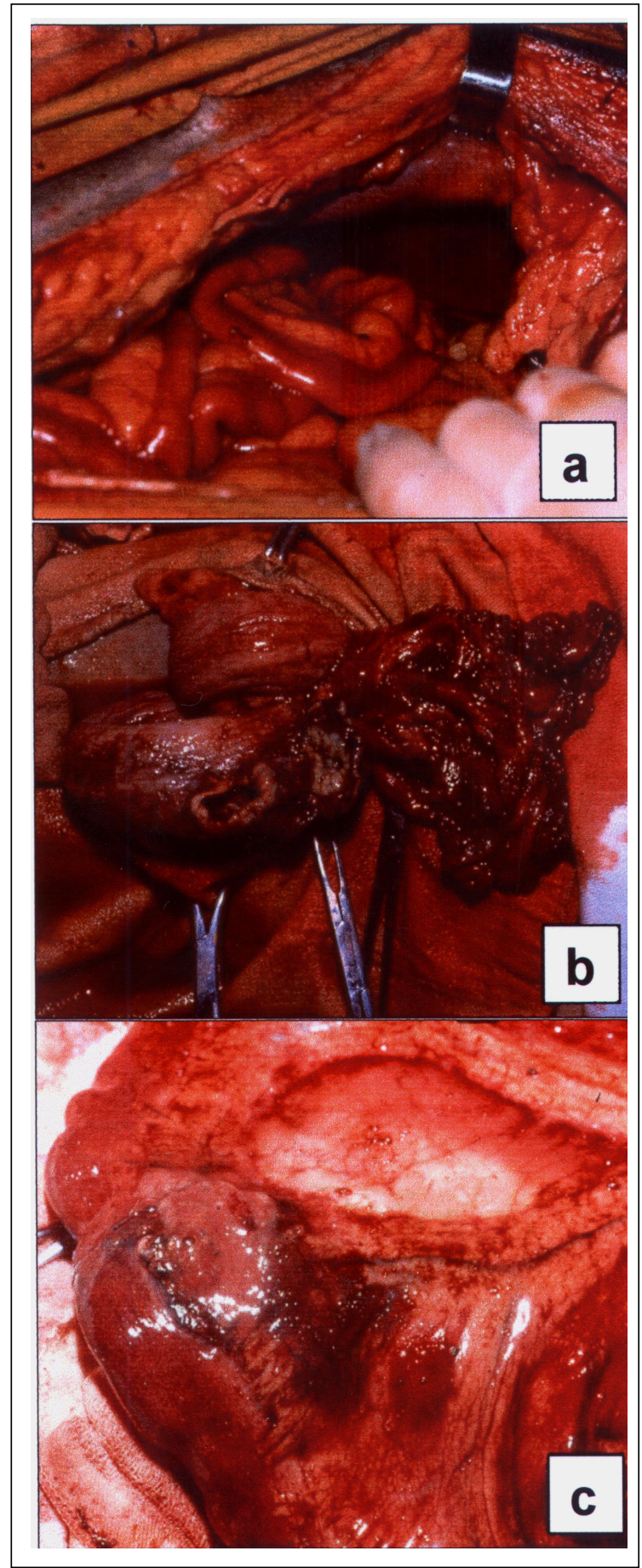

Figura 1 - a) peritonite química (asséptica) por ruptura de lobo hepático em uma cadela Rottweiller atropelada 36h antes; b) peritonite séptica em cadela Pastor alemão com útero rompido em conseqüência de piometrite de colo fechado; c) Rottweiller macho ferido por projétil de arma de fogo no abdome, 6h antes, com peritonite séptica e apresentando petéquias e sufusões no mesentério por coagulação intravascular disseminada (Hospital Veterinário, Universidade Federal de Santa Maria).

Ciência Rural, v.36, n.5, set-out, 2006. 
distensão abdominal, dor à palpação, vômito e diarréia podem ser verificados nos casos de peritonite secundária, em que a infecção sistêmica também pode estar associada com choque séptico (STRAUSS \& CALY, 2003). Em peritonites primárias, os achados são variados e raramente é visualizada dor abdominal (CROWE Jr \& BJORLING, 1998). A peritonite séptica em cães geralmente está associada com dor exacerbada e difusa no abdome (BOAG \& HUGHES, 2004; BEAL, 2005), mas o uroabdome e a peritonite biliar podem ser ou não dolorosas (BOAG \& HUGHES, 2004). Cães com peritonite, quando em estação, exibem uma postura de dorso arqueado, apoio nos cotovelos e fronte baixa, conhecida como postura de prece (STAATZ, 2002).

Pacientes de SRIS podem apresentar, na fase hiperdinâmica, mucosas congestas, pulso forte e rápido, tempo de reperfusão capilar diminuído, moderada taquicardia e pirexia. Na presença de hipovolemia grave, a taquicardia é acentuada (170200bat $\min ^{-1}$ ), o pulso femoral é fraco, a reperfusão capilar aumentada, detectando-se normo ou hipotermia (SWANN \& HUGHES, 2000).

Na maioria das vezes, exames radiográficos e ultra-sonográficos auxiliam o diagnóstico da origem da afecção. Pela imagem radiográfica da cavidade abdominal, evidencia-se aumento de radiopacidade difusa ou localizada; a serosa não é claramente visualizada, e os órgãos perdem definição devido à presença de fluido intracavitário. Grande quantidade de líquido causa opacidade e deve ser diferenciado de carcinomas metastáticos (KEALY \& McALLISTER, 2005).

A imagem ultra-sonográfica sugere a presença de peritonite quando houver partículas oscilantes no líquido abdominal, com ou sem linhas de cauda (tags) e de fibrina (hiperecóicas). A superfície serosa dos órgãos adjacentes pode mostrar contorno irregular (KEALY \& McALLISTER, 2005). O ultra-som oferece o modo mais rápido para detectar pequenos derrames na cavidade abdominal e pode guiar a sua aspiração para análise citológica e bioquímica, que é a maneira mais rápida de diagnosticar peritonite séptica (BOAG \& HUGHES, 2004; BEAL, 2005).

Os exames laboratoriais são importantes principalmente para o diagnóstico de peritonite assintomática. A avaliação laboratorial do líquido ascítico permite diferenciar a sua origem e precisar o diagnóstico (STRAUSS \& CALY, 2003). A sua colheita é feita por meio de paracentese ou lavado abdominal com posterior exame citológico. O lavado está indicado na ausência de líquido durante aspiração por paracentese e consiste na administração de 25-30ml $\mathrm{kg}^{-1}$ de solução de Ringer lactato na cavidade abdominal, com auxílio de um cateter de múltiplos orifícios. Após isso, deve-se realizar movimentos de rotação do animal para que a solução percorra todos os tecidos da cavidade, permitindo que a nova colheita seja fidedigna para exame citológico, cultura e antibiograma (CROWE Jr \& BJORLING 1998).

O líquido obtido pelo lavado peritoneal, além de ser submetido a exame macroscópico, deve ter determinado o hematócrito (presença de sangue), a proteína total, ser feita citologia e, especialmente na peritonite biliar ou urinária, estão indicadas a análise bioquímica e bacteriológica (BOAG \& HUGHES, 2004).

Segundo CONALLY (2003), a citologia do derrame peritoneal de um paciente com enfermidade abdominal aguda pode ser uma ferramenta decisiva para o diagnóstico rápido, necessário para o início de uma oportuna e apropriada terapia. A avaliação da amostra do líquido é muitas vezes útil na identificação do mecanismo que está causando o derrame, podendo ocasionalmente resultar no diagnóstico específico.

Achados de neutrófilos degenerados tóxicos e bactérias, na avaliação citológica, comprovam a vigência de peritonite séptica. A leucometria no lavado abdominal de animais acometidos é de $4.000 \mathrm{~mm}^{-3}$, enquanto que em animais sadios, antes da cirurgia, não passa de $1.000 \mathrm{~mm}^{-3}$ (CROWE Jr \& BJORLING, 1998).

Hemograma e exames bioquímicos são úteis no diagnóstico de peritonite; entretanto, várias enfermidades têm resultados semelhantes. Segundo BOAG \& HUGHES (2004), pacientes com vasculite por peritonite séptica comumente apresentam queda nos valores das proteínas totais sem afetar o hematócrito. Já no uroperitônio há elevação na uréia nitrogenada do sangue, na creatinina e no fósforo, enquanto na peritonite biliar há elevação na bilirrubina total. Para TILLER \& COWELL(1989)e SWAN \& HUGHES (2000), a concentração de creatinina no líquido abdominal é maior que a concentração de creatinina sérica, o que confirma o diagnóstico de uroperitônio.

BONCZYNSKI et al. (2003) avaliaram o pH, o bicarbonato, a concentração de glicose e o lactato no sangue e no líquido peritoneal de cães e gatos com peritonite. Os autores concluíram que uma diferença maior que $20 \mathrm{mg} \mathrm{dL}^{-1}$ entre a concentração de glicose no sangue e no líquido peritoneal provê rápido e confiável meio para diferenciar um derrame séptico de um asséptico em cães e gatos, com 100\% de especificidade e sensibilidade.

\section{Tratamento}

O tratamento da peritonite deve ser dirigido para a estabilização sistêmica do paciente, localizar e 
corrigir a causa, drenar a cavidade abdominal, instituir os cuidados pós-operatórios e de suporte nutricional (PAPAZOGLOU \& RALLIS, 2001; STAATZ, 2002).

O tratamento do paciente portador de infecção intra-abdominal deve ser agressivo, preciso e rápido (FERRAZ \& FERRAZ, 2005). O controle adequado do foco infeccioso é o principal fator de influência na redução da mortalidade desse tipo de paciente. Tratando-se de peritonite primária não há indicação para intervenção cirúrgica, devendo-se tratála com antibióticos que atuem sobre os patógenos envolvidos e isolados através de culturas, evitando a antibioticoterapia empírica. O tratamento preconizado para a peritonite secundária compreende: estabilização hemodinâmica, imunológica e metabólica; terapia antimicrobiana; controle do foco infeccioso e remoção do fator desencadeante (BOURGOIN, 2004; FERRAZ \& FERRAZ, 2005).

No animal com instabilidade hemodinâmica, especialmente em decorrência de choque séptico, está indicada reposição agressiva de líquidos, que, pode ser iniciada com solução de Ringer lactato. Recomendase, no entanto, primeiramente determinar os valores do hematócrito e das proteínas do plasma, pois, em decorrência da espoliação protéica, especialmente nas peritonites crônicas, soluções poliônicas podem comprometer seriamente a pressão coloidosmótica, com risco de edema em órgãos vitais. A associação de expansores do plasma, na proporção de 1:4 em relação à solução cristalóide assegura reposição hidroeletrolítica e de proteínas do plasma diminuindo o risco de edema por diluição. Nos pacientes em choque, deve-se preferir inicialmente o uso de poligelinas (Polisocel $^{\circledR}$ - Halex Histar), que possuem baixo peso molecular (35000D) e expandem rapidamente a volemia. Como as poligenlinas permanecem por tempo reduzido no leito vascular (2-4h), se for necessária a manutenção da pressão oncótica, recomenda-se administrar o hidroxietilamido (Plasmin ${ }^{\circledR}-$ Halex Histar), que se mantém circulante por até 25 horas em função de seu alto peso molecular (450000D). Nos casos em que, não só o valor da proteína do plasma mas também o do hematócrito estiverem baixos, é necessária transfusão de sangue recém colhido, particularmente se houver sinais de incoagulabilidade do sangue (RAISER, 2005).

A velocidade de administração do Ringer lactato, na reposição da volemia, é em regra geral, de $90 \mathrm{ml} \mathrm{kg}^{-1} \mathrm{~h}^{-1}$ (SWAN \& HUGEHS, 2000; PLUNKETT, 2001). No entanto, BEAL (2005) prefere iniciar com a administração venosa, em "bolus” de $25-30 \mathrm{ml} \mathrm{kg}^{-1}$ durante 15 minutos, seguida de reajuste da dose, conforme a resposta na freqüência cardíaca, a coloração de mucosas, o tempo de reperfusão capilar, a pressão sangüínea, o débito uirinário, o nível de bicarbonato no sangue ou o excesso de base e lactato. Em relação ao uso de expansores do plasma, BEAL (2005) recomenda o Hetastarch a 6\% (derivado da amilopectina) em dose de $5-20 \mathrm{ml} \mathrm{kg}^{-1}$.

Considera-se que uma maneira prática de estabelecer a velocidade de administração de fluidos, na rotina da clínica cirúrgica, seja pela monitorização da pressão venosa central (evitar que ultrapasse 10$15 \mathrm{~cm} \mathrm{H}_{2} 0$ durante a fluidoterapia), do débito urinário (evitar que ultrapasse $2 \mathrm{ml} \mathrm{kg}^{-1} \mathrm{~h}^{-1}$ ), da coloração das mucosas, do tempo de reperfusão capilar e pela estimativa clínica da pressão arterial. A pressão venosa central pode ser determinada pela colocação de um cateter periférico na veia jugular, usando-se um fator de correção $(-0,51)$, que é subtraído do resultado obtido na leitura do manômetro (AGUIAR et al., 2004). Os autores desta revisão consideram os seguintes parâmetros para estimar clinicamente a pressão arterial: para pulso presente na artéria femoral e carpiana ou metatarsiana, estima-se pressão acima de $80 \mathrm{mmHg}$; para pulso presente na artéria femoral e ausente na artéria carpiana ou metatarsiana, estima-se pressão ao redor de 60mmHg; e para ausência de pulso periférico palpável, mas bulhas cardíacas auscultáveis, estimase pressão ao redor de $50 \mathrm{mmHg}$. Deve-se ter em conta que o sistema nervoso central não é adequadamente perfundido quando a pressão sangüínea estiver abaixo de 50mmHg. Portanto, nessas situações de ausência de pulso periférico, deve-se expandir a volemia rapidamente para evitar a possibilidade de lesão neurológica isquêmica.

Pacientes submetidos à adequada oxigenação e perfusão tecidual tendem a estabilizar seu equilíbrio ácido-base. Entretanto, naqueles em que houver acidose persistente, confirmada por gasometria, a reposição é feita com base no excesso de base. Pela estimativa clínica (pacientes de acidose apresentam hipotermia, arritmia cardíaca e podem ter alteração sensorial), o bicarbonato de sódio deve ser administrado em dose de $2-4 \mathrm{mEq} \mathrm{kg}{ }^{-1}$, diluído em cloreto de sódio isotônico e administrado por via intravenosa, em período não inferior a 2-4h (RAISER, 2005).

Considerando que a peritonite causa grave espoliação hidroeletrolítica, em especial do potássio, deve-se procurar repor esse eletrólito mediante a diluição de $14 \mathrm{mEq}$ de $\mathrm{KCl}$ (1 ampola de 10ml a 10\%) em um litro de Ringer lactato, e administrar, por gotejamento venoso, em velocidade inferior a $25 \mathrm{ml} \mathrm{kg}^{-1} \mathrm{~h}^{-1}$, evitando assim o risco de interferir prejudicialmente na atividade elétrica do coração. 
A antibioticoterapia deve ser instituída rapidamente. A realização da cultura e do antibiograma é extremamente recomendada, pois esse exame indicará a sensibilidade correta das bactérias patogênicas (FERRAZ \& FERRAZ, 2005). O antibiótico escolhido deve ter efeito amplo, inclusive sobre anaeróbicos, ou ser associado ao metronidazole. As cefalosporinas de primeira geração devem ser associadas às de terceira geração (FARMÁCIA MÉDICA, 2005), ou com uma fluorquinolona, como o enrofloxacino, ou com uma cefalosporina de segunda geração (SWANN \& HUGHES, 2000). Em nossa rotina, o antibiótico é selecionado por antibiograma, calculado em função da sua constante de eliminação (RAISER, 2005) e administrado de forma contínua, por $24 \mathrm{~h}$, mediante diluição em solução hidroeletrolítica, conforme a seguinte fórmula:

quantidade $\left(\mathrm{mg} \mathrm{kg}^{-1}\right)$ = peso do cão $(\mathrm{kg}) \mathrm{x}$ mg kg-1 (do antibiótico) constante de eliminação x 24h.

A dor causada pela peritonite é classificada de moderada a grave. Para esses casos, indicam-se como analgésicos o butorfanol $\left(0,4 \mathrm{mg} \mathrm{kg}^{-1}\right)$, ou o cloridrato de fentanila $\left(0,001-0,005 \mathrm{mg} \mathrm{kg}^{-1}\right)$. A morfina livre de conservantes ( $\left.1 \mathrm{mg} \mathrm{ml}^{-1}\right)$ e a bupivacaína $0,25 \%$, na proporção de 1:1, quando administradas em "bolus”, via epidural, lentamente $\left(0,1 \mathrm{ml} \mathrm{kg}^{-1}\right)$, seguindo-se da administração continuada (por bomba de infusão) na dose de $0,4-0,8 \mathrm{ml} \mathrm{kg}^{-1} \mathrm{dia}^{-1}$, proporcionam excelente grau de analgesia em pacientes de peritonite (MATHEUS \& DYSON, 2005).

O objetivo do tratamento cirúrgico nas peritonites bacterianas é de: identificar e remover a fonte de contaminação ou infecção, prevenir contaminação recorrente, reduzir a carga bacteriana na cavidade abdominal, remover corpos estranhos e fragmentos necróticos, proporcionar drenagem e estabelecer acesso enteral para futura nutrição (HOUSE \& BROCKMAN, 2004).

A diminuição da carga bacteriana e a remoção de fragmentos necróticos e de corpos estranhos são obtidas com maior sucesso pela lavagem da cavidade abdominal com abundante volume de solução salina ou com Ringer lactato mornos (SWANN \& HUGHES, 2000; PAPAZOGLOU \& RALLIS, 2001; HOUSE \&BROCKMAN, 2004). A eficiência será maior se a lavagem for repetida tantas vezes quantas sejam necessárias para que a solução seja aspirada limpa (e toda ela deve ser drenada completamente), o que pode requerer de 5 a 7 litros de solução. SLIM (2003) alega que a lavagem abundante da cavidade abdominal durante a intervenção cirúrgica em paciente de peritonite aguda é mais um ritual do que um procedimento válido. Segundo ele, não há certeza de seu efeito benéfico nem de sua inutilidade, pois, ao mesmo tempo em que diminuem os microorganismos presentes no líquido, perdem-se junto elementos de defesa do peritônio.

A adição de antibiótico ou de anti-séptico na solução de lavagem da cavidade abdominal não tem qualquer vantagem e pode trazer complicações como aumento na irritabilidade do peritônio e acidose metabólica, especialmente quando se associa o iodo, que tem sido relacionado com elevação na taxa de óbito. Estudos experimentais comprovam que há diminuição da formação de abscessos e aumento da taxa de sobrevida após o uso intra-abdominal ou subcutâneo da heparina. Outras substâncias vêm sendo testadas, como o óxido nítrico, que promove o relaxamento de células musculares lisas tanto no sistema vascular como em outros tecidos (músculo liso e intestinal) e inibe aderências e agregação plaquetária, com resultados promissores (KREIMER, 2005). Nos casos tratados pelos autores do presente estudo, a lavagem da cavidade abdominal tem sido efetuada apenas com solução de Ringer lactato, a qual possui pH mais alcalino que a de $\mathrm{NaCl}$ a $0,9 \%$. Assim, constatou-se que, nas peritonites tratadas com cavidade aberta não houve evidência de aderência visceral até o fechamento definitivo do abdome.

NAWROCKI et al. (2005) avaliaram a temperatura corporal em cães submetidos a lavagem abdominal com solução salina aquecida a $43^{\circ} \mathrm{C}$ ou em temperatura ambiente. Eles constataram que a temperatura corporal diminuiu nos animais em que se utilizou a solução na temperatura ambiente e que subiu significativamente, a partir dos dois até os 15 minutos, naqueles lavados com solução salina aquecida. Essa preocupação com a temperatura da solução de lavagem é importante em pacientes de peritonite para evitar o agravamento da hipotermia.

Controvérsia tem surgido quanto a conduta subseqüente à laparotomia exploratória, em relação à drenagem do exsudato que continua a se acumular na cavidade abdominal, em particular nas peritonites sépticas, nas quais é difícil remover completamente os agentes contaminantes e os fragmentos necróticos. STAATZ et al. (2002) compararam a drenagem peritoneal aberta com a fechada em 36 cães e em seis gatos com peritonite séptica e constataram que não houve diferença significativa em termos de sobrevivência. Segundo eles, a drenagem peritoneal aberta requereu administração de plasma e jejunostomia em maior número de pacientes, além de ocasinar internação mais prolongada em unidades de tratamento intensivo que a drenagem fechada. Por outro lado, para autores como BRAY (1996), CROWE Jr \& BJORLING (1998), PAPAZOGLOU \& RALLIS, (2001), FOSSUM (2002), WINGFIELD \& RAFFE (2002) e HOUSE \&

Ciência Rural, v.36, n.5, set-out, 2006. 
BROCKMAN (2004), a drenagem aberta da cavidade abdominal facilita a remoção do líquido contaminado intra-cavitário, favorece a re-exploração e torna o meio aeróbico, o que favorece a função dos macrófagos e reduz os microrganismos anaeróbicos. Porém, segundo SWANN \& HUGHES (2000) e WINGFIELD \& RAFFE (2002), podem ocorrer complicações como hipoproteinemia e infecção nosocomial.

Na experiência dos autores desta revisão, a lavagem da cavidade abdominal sempre traz vantagens, especialmente se associada com drenagem continuada da cavidade, pois remove os resíduos necróticos, os exsudatos e a fibrina, que favorecem a proliferação bacteriana e dificultam a ação das defesas orgânicas. A drenagem abdominal com a cavidade fechada tem sido efetuada apenas nos casos em que se fez remoção do epíploo (Figura 2a), pois este comumente obstrui o dreno. Nessa condição, é melhor efetuar drenagem aberta (Figura 2b), em que a abertura é protegida por compressa de gaze estéril associada a uma fralda absorvente.

O suporte nutricional deve ser agressivo, preferencialmente por via enteral. Por essa via, ele maximiza a possibilidade de um resultado positivo (BEAL, 2005), pois melhora de maneira geral a habilidade do organismo em lidar com a capacidade de translocação bacteriana e diminuí-la, reduzindo a resposta catabólica e dos níveis de cortisol no plasma (FERRAZ \& FERRAZ, 2005). Em pacientes que não tenham condição de ingestão oral nem estejam vomitando, indica-se a faringostomia ou o tubo de gastrostomia e, para cães com vômito persistente, recomenda-se a jejunostomia (BEAL, 2005). PLUNKETT (2000) recomenda a administração mínima de $25 \%$ de proteína nas primeiras $12 \mathrm{~h}$ e de $75 \%$ nas 72 $96 \mathrm{~h}$ subseqüentes, em animais com peritonite.

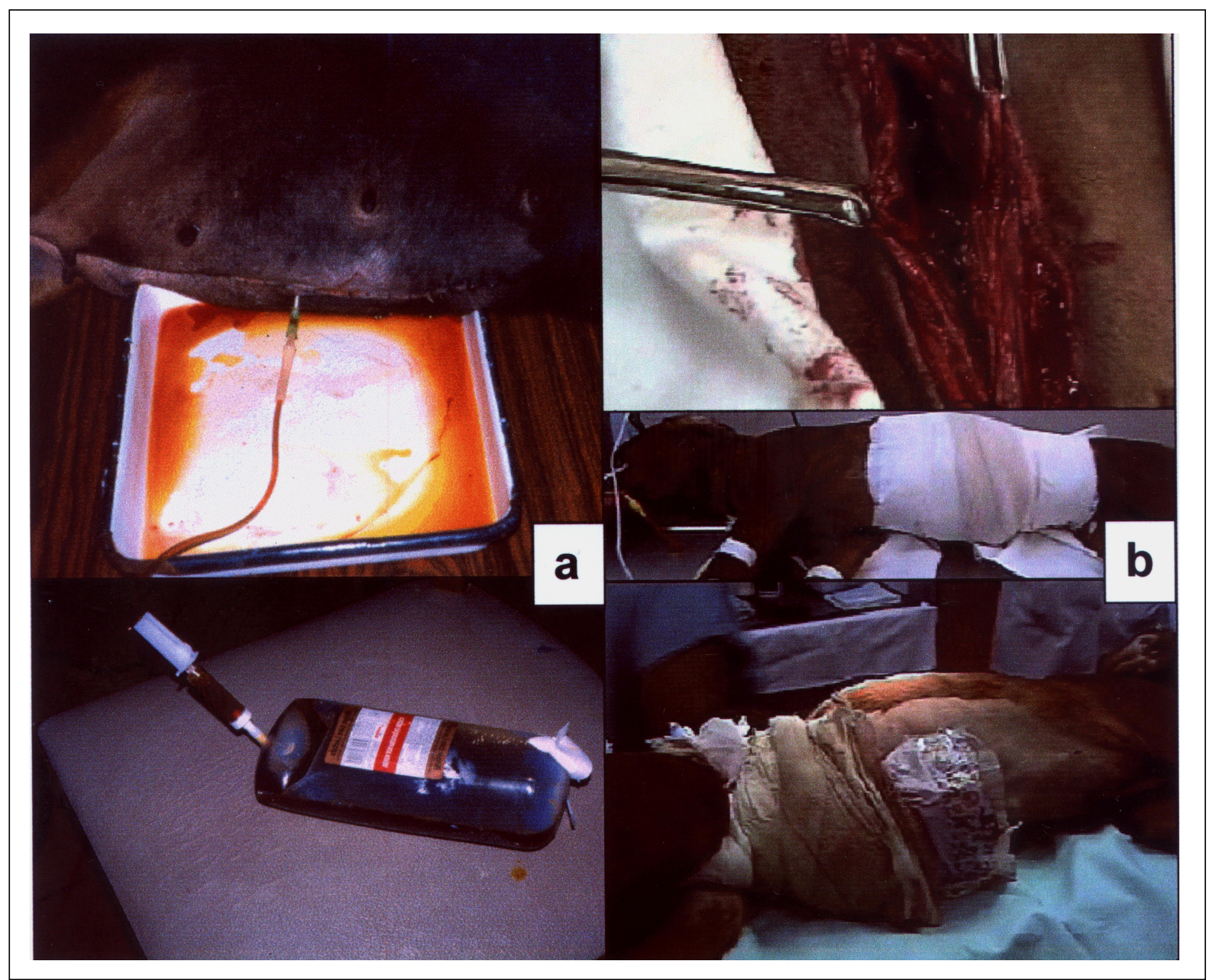

Figura 2 - a) drenagem peritoneal com cateter em cadela Rottweiller com peritonite química por derrame biliar, em que foi efetuada epiplectomia; b) drenagem peritoneal aberta em cão Boxer com peritonite por ruptura vesical. Observar bandagem embebida por exsudato peritoneal após 8h de drenagem aberta (Hospital Veterinário, Universidade Federal de Santa Maria).

Ciência Rural, v.36, n.5, set-out, 2006. 
A nutrição enteral previne, também, a atrofia da mucosa intestinal, porém caso a função intestinal seja inadequada, deve-se optar pela nutrição parenteral (SWANN \& HUGHES, 2000; FERRAZ \& FERRAZ, 2005; BEAL, 2005). A terapia nutricional, além de prevenir e tratar deficiências de componentes dietéticos, tem obtido respostas semelhantes às de agentes farmacológicos, de tal modo que melhora a resposta imunológica dos pacientes. Uma grande variedade de nutrientes apresenta ações imunoestimuladoras: o ácido graxo ômega 3 atua sobre o ácido araquidônico diminuindo a produção de eicosanóides; a glutamina é um aminoácido não essencial, considerado combustível primário para linfócitos, macrófagos e enterócitos (BRADY \& KING, 2000; FERRAZ \& FERRAZ, 2005; FREIRE \& RABELO, 2005); a arginina é um aminoácido semi-essencial, que funciona como potente estimulador do hormônio do crescimento, da prolactina, da insulina pancreática e do glucagon, modulando o metabolismo protéico e aumentando a retenção de nitrogênio, além de aumentar a síntese do colágeno e diminuir os efeitos do traumatismo sobre a resposta linfocitária periférica (FERRAZ \& FERRAZ, 2005; FREIRE \& RABELO, 2005). No paciente de peritonite, devem ser monitorizados diariamente os parâmetros de coagulação (contagem plaquetária, tempo de trombina parcial e de protrombina) para prevenir o desenvolvimento da coagulação intravascular disseminada. Na vigência de distúrbio de coagulação, a terapia consiste em remover a causa, em repor fluido, em oxigenar e em administrar plasma, e, na fase de coagulopatia de consumo, em fazer heparinização sistêmica do paciente (PLUNKETT, 2001; RAISER, 2005).

O uso de corticosteróides é controvertido em condições de infecção sistêmica. Por essa razão, os autores desta revisão têm utilizado a aplicação em “bolus” (dexametasona) apenas na cavidade abdominal, após cada lavagem, para minimizar a irritação peritoneal. Como na peritonite esta serosa apresenta processo exsudativo, o fármaco não é absorvido por via sistêmica.

\section{CONCLUSÃO}

Em face da morbidade por peritonite, o diagnóstico e o início da terapia devem ser precoces para que se tenha prognóstico mais favorável. A radiografia e a ultra-sonografia oferecem importante apoio diagnóstico, mas o exame laboratorial do derrame facilita o diagnóstico de peritonite e seu prognóstico e orienta o tratamento.
A terapia deve incluir a laparotomia exploratória, especialmente na peritonite bacteriana, e o estabelecimento de drenagem continuada. Em pacientes submetidos à epiplectomia, a drenagem pode ser fechada, com adaptação de dreno, e, nas demais, a técnica aberta é mais eficiente. Não há indicação para associar antibióticos ou anti-sépticos na solução de lavagem da cavidade, porém a escolha, a precocidade e a manutenção contínua dos níveis séricos do agente antimicrobiano são fundamentais para a sobrevivência do animal. Uma correta e balanceada nutrição enteral favorece a recuperação do paciente e colabora para manter a integridade da barreira intestinal. Cada indivíduo responde de forma diferenciada ao tratamento e isto deve ser considerado em todas as etapas de atendimento ao paciente de peritonite.

\section{REFERÊNCIAS}

AGUIAR, E.S.V. et al. Mensuração da pressão venosa central por meio de cateteres venosos central e periférico: comparação entre os valores obtidos em cães e elaboração de índices de correção. Ciência Rural, Santa Maria, v.34, n.6, p.18271831, 2004.

BEAL, M.W. Approach to the acute abdomen. Veterinary Clinics of North America: Small Animal Practice, Philadelphia, v.35, n.2, p.375-396, 2005.

BOAG, A.; HUGHES, D. Emergency management of the acute abdomen in dogs and cats 1 . Investigation and initial stabilization. In Practice, London, v.26, n.9, p.476-483, 2004.

BONCZYNSKI, J.J. et al. Comparison of peritoneal fluid and peripheral blood $\mathrm{pH}$, bicarbonate, glucose, and lactate concentration as a diagnostic tool for septic peritonitis in dogs and cats. Veterinary Surgery, Davis, v.32, n.2, p.161-166, 2003.

BOURGOIN, A. et al. Prise en charge thérapeutique des peritonitis. Medicine et maladies infectieuses, Marceille, v.34, p.183-195, 2004.

BRADY, C.A.; KING, L.G. Postoperative management of the emergency small animal patient. Veterinary Clinics of North America: Small Animal Practice, Philadelphia, v.30, n.3, p.681-697, 2000.

BRAY, J. Diagnosis and management of peritonitis in small animals. In Practice, London, v.18, n.9, p.403-413, 1996.

CONALLY, H.E. Cytology and fluid analysis of the acute abdomen. Clinical Techniques in Small Animal Practice, Orlando, v.18, n.1, p.39-44, 2003.

CROWE Jr., D.T.; BJORLING, D.E. Peritônio e cavidade peritoneal. In: SLATTER, D. Manual de cirurgia de pequenos animais. São Paulo: Manole, 1998. Cap. 34, p.499-528.

DULISH, M.L. Peritonite. In: BOJRAB, M.J. Mecanismos da moléstia na cirurgia dos pequenos animais. 2.ed. São Paulo: Manole, 1996. Cap.17, p.128-132. 
FARMÁCIA MÉDICA. Beta-lactâmicos. Capturado em 6 out.2005. Online. Disponível na Internet http:// geocities.yahoo.com./cyjr2000/cefalo3.htm.

FERRAZ, B.A.A; FERRAZ, M.E. Fisiopatologia da sepse. In: MARTINS, N. Programa de atualização em uso de antibióticos em cirurgia. Rio de Janeiro: Diagraphic, 2002. Ano I, v.1, n.2, 2005. Capturado em 5 out.2005. 20:44. Online. Disponível na Internet http://www.cbc.org.br/atualização/ fascículos131/antibioticoterapia.htm.

FOSSUM, W.T. Cirurgia da cavidade abdominal. In: Cirurgia de pequenos animais. São Paulo: Roca, 2002. Cap. 15, p.199-221.

FREIRE, M.; RABELO, R.C.R. Translocação bacteriana. In: RABELO, R.C.; CROWE Jr., D.T. Fundamentos de terapia intensive veterinária em pequenos animais. Conduta no paciente crítico. Rio de Janeiro: LF Livros, 2005. Cap.13, p.127-135.

HOUSE, A.;BROCKMAN, D. Emergency management of the acute abdomen in dogs and cats 2 . Surgical treatment. In Practice, London, v.26,n10, p.530-537, 2004.

JUTKOWITZ, L.A. Reproductive emergencies. Veterinary Clinics of North America: Small Animal Practice, Philadelphia, v.35, n.2, p.397-420, 2005.

KEALY, J.K.; McALLISTER, H. O abdome. In Radiologia e ultra-sonografia do cão e do gato. 3.ed. São Paulo: Manole, 2005. p.19-148.

KREIMER, F. et al. Resposta terapêutica e inflamatória de ratos com peritonite secundária submetidos ao uso tópico de ampicilina/sulbactam. Acta Cirurgica Brasileira, São Paulo, v.20, supl.1, p.31-39, 2005.

MATHEWS, K.A.; DYSON, D.H. Analgesia and chemical restraint for the emergent patient. Veterinary Clinics of North America:Small Animal Practice, Philadelphia, v.35, n.2, p.481-515, 2005

NAWROCKI, M.A. $t$ al. The effects of heated and roomtemperature abdominal lavage solutions on core body temperature in dogs undergoing celiotomy. Journal of the
American Animal Hospital Association, Lakewood, Co., v.41, n.1, p.61-67, 2005

PAPAZOGLOU, L.G.; RALLIS, T. Diagnosis and surgical management of septic peritonitis in the dog and cat. Walthan Focus, Leicestershire, v.11, n.2, p.9-14, 2001.

PLUNKETT, S.J. Emergency procedures for the small animal veterinarian. Philadelphia: Saunders, 2000. 574p.

RAISER, A.G. Choque. In: RABELO, R.C.; CROWE Jr., D.T. Fundamentos de terapia intensive veterinária em pequenos animais. Conduta no paciente crítico. Rio de Janeiro: LF Livros, 2005. Cap.10, p.71-104.

RIESER, T.M. Urinary tract emergencies. Veterinary Clinics of North America: Small Animal Practice, Philadelphia, v.35, n.2, p.359-373, 2005

SWANN, H.; HUGHES, D. Diagnosis and management of the peritoneal cavity. Veterinary Clinics of North America:Small Animal Practice, Philadelphia, v.30, n.3, p.603-615, 2000.

SLIM, K. Le lavage péritoneal: une necessité ou un ritual nocturne sans preuvi scientifique? Annales de chirurgie, Clermont-Ferrand, n.128, p.221-222, 2003.

STAATZ, A.J. Peritonitis. In: WINGFIELD, W.E.; RAFFE, M.C. The veterinary ICU book. Jackson Hole, Wyoming: Teton NewMedia, 2002. Sec. IV, Chapt.48, p.724-730.

STRAUSS, E; CALY, R.W. Peritonite bacteriana espontânea. Revista da Sociedade Brasileira de Medicina Tropical, São Paulo, v.36, n.6, p.711-717, 2003.

TILLER, R.D.; COWELL, R.L. Avaluation of pleural and peritoneal effusions. Veterinary Clinics North America: Small Animal Pract, Philadelphia, v.19, n.4, p.743-768, 1989.

WINGFIELD, W.E.; RAFFE, M.C. The veterinary ICU book. Jackson Hole: Teton New Media, 2002. 1337p.

WONG, P.F. Antibiotic regimens for secondary peritonitis of gastrointestinal origin in adults. In: Cochrane review abstracts, 2005. Acesso em 20/outubro/2005. On line. Disponível em: http://www.medscape.com/viewarticle/511474, 